\title{
LABORATÓRIO COLABORATIVO EM ARTE E EDUCAÇÃO: PROCESSOS DE CRIAÇÃO EM GRUPO ENTRE EDUCADORES
}

\author{
COLLABORATIVE LABORATORY IN ART AND EDUCATION: \\ CREATION PROCESS IN GROUPS AMONG EDUCATORS
}

Ariane Alfonso Azambuja de Oliveira Salgado Mestre em Patrimônio e Museologia Pontifícia Universidade Católica de São Paulo - PUC-SP

Curitiba, Paraná - Brasil arianeazambuja@gmail.com

Bruno Ferreira de Souza Licenciado em Artes Visuais Universidade Federal do Paraná - UFPR Curitiba, Paraná - Brasil brunoferreira_501@hotmail.com

Cecília Almeida Salles Doutora em Linguística Aplicada e Estudos de Línguas Pontifícia Universidade Católica de São Paulo - PUC-SP São Paulo - Brasil cecilia.salles@gmail.com

\begin{abstract}
Resumo:O artigo apresenta uma análise sobre os processos de criação em grupo ocorridos no projeto de educação não formal Laboratório Colaborativo em Arte e Educação, desenvolvido durante o ano de 2018 entre a galeria de arte da CAIXA Cultural Curitiba e três escolas da cidade de Curitiba. A análise é realizada a partir de documentos de processos arquivados, como fotografias, desenhos, vídeos, chats, avaliações por escrito, entre outros, que indicam os movimentos de diversos sujeitos envolvidos no projeto (professores, educadores de museus, estudantes, famílias e artistas) para a criação dos planejamentos. O estudo tem como objetivo avaliar, de um ponto de vista qualitativo, o diálogo obtido entre museu e escola. A metodologia utilizada tem como base teórica a crítica de processos criativos, de Cecília Almeida Salles; a reflexão sobre diálogo é desenvolvida a partir de Paulo Freire; e as autoras Maria da Glória Gohn e Michèle Petit sustentam os debates sobre planejamento, mediação cultural e educação não formal no campo da arte. Compreendemos a partir da pesquisa que a avaliação de uma ação educativa será tanto mais rica quanto mais documentos possuirmos para relacionar entre si e que a abertura para as transformações do planejamento durante cada experiência do projeto favoreceu a qualidade do diálogo entre as escolas e o museu e constituíram em si parte do próprio diálogo.
\end{abstract}

Palavras-chave: Avaliação. Diálogo. Educação não formal. Museu de arte. Processo de criação em grupo.

\begin{abstract}
This article presents an analysis of the creation processes in groups from the project of non-formal education Laboratório Colaborativo em Arte e Educação (Collaborative Laboratory in Art and Education, in Portuguese), which occurred during 2018 at the art gallery that belongs to CAIXA Cultural Curitiba and at three schools in Curitiba, Brazil. The analysis is based on process documentation that has been stored, such as photographs, drawings, videos, text messages, written evaluation, among others, which show how the different subjects involved at the project (teachers, museum educators, students, families and artists) acted in order to create their planning. The study intends to evaluate, from a qualitative point of view, the resulting dialog between museum and school. The methodology has a theoretical basis on the creative process criticism by Cecília Almeida Salles; the reflection on dialog is developed based on Paulo Freire; and authors Maria da Glória Gohn and Michèlle Petit are a support for the discussion on planning, cultural mediation and non-formal education on art. After the research we understand that the evaluation of an educational action will be progressively more meaningful the more documents we find to relate among each other; we also understand that the opening for the transformations in the planning during each experience of the project improved the quality of the dialog between the schools and the museum and became a part of the dialog itself.
\end{abstract}

Keywords: Evaluation. Dialog. Non-formal education. Art museum. Creative process in groups.

Para citar - (ABNT NBR 6023:2018)

SALGADO, Ariane Alfonso Azambuja de Oliveira; SOUZA, Bruno Ferreira de; SALLES, Cecília Almeida. Laboratório colaborativo em arte e educação:processos de criação em grupo entre educadores. Eccos - Revista Científica, São Paulo, n. 56,

p. 1-23, e16645, jan./mar. 2021. Disponível em: https://doi.org/10.5585/eccos.n56.16645. 


\section{Introdução}

A aspiração por aprofundar a compreensão sobre o potencial educativo de uma galeria pública de arte foi o ponto de partida para a criação do projeto cujos resultados apresentamos e discutimos ao longo deste texto. A citada galeria é um dos espaços mantidos nos centros culturais da CAIXA Cultural, programa do banco CAIXA Econômica Federal. O Laboratório Colaborativo em Arte e Educação foi concebido e desenvolvido na galeria da CAIXA Cultural Curitiba, no âmbito do Programa Educativo Gente Arteira, ao longo do ano de 2018. Esta escrita, de autoria compartilhada entre os idealizadores do Laboratório (que, à época de realização do projeto, ocupavam os cargos de Orientadora Pedagógica ${ }^{1}$ e Educador ${ }^{2}$ do citado Programa), reúne reflexões sobre essa experiência educativa em uma análise embasada na crítica de processos criativos, de Cecília Almeida Salles ${ }^{3}$ (2010, 2014, 2017), que é igualmente autora do artigo. Serão explorados no estudo questões sobre a natureza do diálogo entre escola e museu ou, categorizando de maneira mais geral, do diálogo entre educação formal e não formal, e o desafio de avaliar qualitativamente ações educativas que aproximam esses dois espaços.

Projetos desenvolvidos por programas educativos de museus e galerias de arte possuem diferentes concepções no que se refere ao nível de diálogo obtido com as escolas. Há experiências em que esses contatos são apenas conversas breves por telefone com os professores, para agendamento das visitas, mas, também, vivências mais amplas, como a que se intentou desenvolver no Laboratório, o qual foi desenvolvido em parceria, com autoria compartilhada entre educadores de museus e docentes das escolas. Neste artigo, faremos uma análise de documentos produzidos e arquivados ao longo de cada uma das três edições do projeto como forma de avaliar o nível de diálogo obtido entre museu e escola.

Nosso conceito de avaliação está embasado nas reflexões de Freire (1996, p. 116, grifos no original) sobre a necessidade de ela ser pensada como um "instrumento de apreciação do que-fazer de sujeitos críticos a serviço [...] da libertação e não da domesticação. Avaliação em que se estimule o falar $a$ como caminho do falar com". Avaliar aqui, portanto, significa realizar uma reflexão sobre a disponibilidade dos diferentes sujeitos envolvidos no

\footnotetext{
${ }^{1}$ Ariane Alfonso Azambuja de Oliveira Salgado exerceu a função de Orientadora Pedagógica do Programa Educativo Gente Arteira da CAIXA Cultural Curitiba no período de março de 2017 a dezembro de 2018. Atualmente é doutoranda no Programa de Pós-Graduação em Comunicação e Semiótica da PUC-SP, na linha de pesquisa Processos de Criação na Comunicação e na Cultura, e integrante do Grupo de Estudos de Processos de Criação. O presente trabalho foi realizado com apoio do CNPq, Conselho Nacional de Desenvolvimento Científico e Tecnológico - Brasil.

${ }^{2}$ Bruno Ferreira de Souza exerceu a função de Educador do Programa Educativo Gente Arteira da CAIXA Cultural Curitiba no período de agosto de 2016 a abril de 2019 e de Orientador Pedagógico do mesmo programa de abril de 2019 a agosto de 2020.

3 Cecília Almeida Salles é professora titular do Programa de Pós-Graduação em Comunicação e Semiótica da PUC-SP e coordenadora do Grupo de Pesquisa em Processos de Criação.
} 
projeto em dialogar para construir aprendizados, o que necessariamente tem relação com a capacidade de escuta de cada um:

Escutar [...] significa a disponibilidade permanente por parte do sujeito que escuta
para a abertura à fala do outro, ao gesto do outro, às diferenças do outro. Isto não
quer dizer [...] que escutar exija de quem realmente escuta sua redução ao outro que
fala. Isto não seria escuta, mas auto-anulação. A verdadeira escuta não diminui em
mim, em nada, a capacidade de exercer o direito de discordar, de me opor, de me
posicionar. Pelo contrário, é escutando bem que me preparo para melhor me colocar
ou melhor me situar do ponto de vista das ideias. Como sujeito que se dá ao discurso
do outro, sem preconceitos, o bom escutador fala e diz de sua posição com
desenvoltura. Precisamente porque escuta, sua fala discordante, em sendo
afirmativa, porque escuta, jamais é autoritária. (FREIRE, 1996, p. 119, grifo no
original)

No que se refere à nossa metodologia, a pesquisa está inserida na esteira dos estudos desenvolvidos por Salles, denominados de crítica de processos criativos. Nesta abordagem, as pesquisas são realizadas a partir dos documentos produzidos pelos artistas ao longo da construção de suas obras; no presente texto, por analogia, analisamos os documentos produzidos pelos educadores ao longo do projeto. Esses documentos possuem diversas naturezas, sendo fotografias, vídeos, desenhos, anotações em cadernos, e-mails, arquivos de word, conversas de WhatsApp, que, ao serem colocados em relação, revelam um "pensamento em construção" (SALLES, 2014, p. 13). O conceito de criação é discutido ao longo do artigo, a partir do contexto do projeto educativo.

É importante esclarecer que esta vertente de estudos é proveniente do campo da crítica genética $^{4}$ e, portanto, não estabelece um conjunto de documentos a serem produzidos a priori, durante os processos de criação, para posterior análise. O movimento que se faz é justamente o contrário: são os documentos que foram espontaneamente criados que são coletados para análise, porque são assim encontrados em seus ambientes de produção e apontam escolhas subjetivas dos sujeitos envolvidos. Nesse sentido, as escolhas de tipos de registro (sua materialidade), por si, já apontam parte do processo. Assume-se com isso que não se tem a ilusão de ter acesso a todo o processo, de se restituir completamente os movimentos da criação; apesar disso, ela é potente o suficiente para apontar tendências dessa trajetória, sempre com mais detalhes na medida em que existam mais documentos que se relacionem entre si. É por esta razão que consideramos a abordagem da crítica de processos criativos coerente com o campo da educação não formal, pois nesta há menor padronização no modo de se registrar as práticas educativas do que em relação à educação formal, especialmente

\footnotetext{
${ }^{4}$ Estudos que foram assim nomeados pelo Institut des Textes et Manuscrits Modernes (ITEM/CNRS/Paris), em 1968, dedicados aos manuscritos literários.
} 
quando não há intencionalidade de pesquisa. Embora seja relativamente comum haver práticas de arquivamento por parte dos profissionais envolvidos (seja a pedido das instituições, seja espontaneamente), esses documentos nem sempre chegam a ser relacionados entre si para produzir conhecimento sobre o campo ou mesmo são analisados isoladamente: são apenas guardados. Esta pesquisa surge, portanto, também da pergunta: como produzir conhecimento sobre práticas educativas a partir dos documentos já arquivados nos setores educativos de museus? No caso do projeto aqui estudado, o corpus se constitui de documentos arquivados pelo Programa Educativo Gente Arteira e arquivos dos oficineiros que coordenaram o projeto, provenientes de seus cadernos e pastas pessoais físicas e virtuais.

A concepção de processo de criação como algo que se desenvolve em diversos âmbitos das práticas sociais, e não somente na arte, é uma premissa que embasa nossa abordagem. Salles (2014, p. 36) afirma que se pode "falar que há criação em um espectro maior dos processos de produção, sejam eles concretizados nas artes ou em qualquer outro meio de comunicação". Para ela, há apenas distinções nos modos como esses processos de desenvolvem: "O que difere, entre muitos aspectos, é a tendência do processo, a natureza dos elementos conectados e os recursos utilizados para tais associações" (2014, p. 36). Entendemos, assim, que o trabalho desenvolvido por educadores é resultado de um processo de criação que pode ser realizado de forma individual ou em grupo, dependendo do contexto onde o projeto educativo está inserido e do desejo do próprio profissional.

Na crítica de processos criativos, o processo de criação da obra é o objeto de estudo, e não a obra de arte como é mostrada ao público; em analogia, acreditamos que na educação isso é equivalente ao estudo dos modos como educadores constroem seus planejamentos, seja de maneira intuitiva ou sistematizada, e não a ação educativa em si. Entretanto, na mesma medida acreditamos que os planejamentos futuros são comumente afetados por aquilo que ocorreu no passado ou está ocorrendo no presente: um novo planejamento leva em consideração, em maior ou menor grau, os resultados obtidos em encontros anteriores com o grupo, tal como propõe Freire (2002, p. 14): “a programação inicial de uma prática, às vezes, é refeita à luz das primeiras avaliações que a prática sofre. Avaliar implica, quase sempre, reprogramar, retificar. A avaliação, por isso mesmo, não se dá apenas no momento que nos parece ser o final de certa prática." No caso do Laboratório, constituído como uma ação continuada de diversos encontros, consideramos importante incluir entre os documentos analisados também os registros de cada encontro em si, como sinais que apontavam para os novos caminhos que seriam trilhados. 
No que se refere à crítica de processos criativos, compreendendo que o objeto de estudo desta teoria é o processo de criação, é importante delimitar também o conceito de criação como "rede em processo" (SALLES, 2014, p. 19). Admitimos, assim, a definição de Salles de que "[a] criação artística é marcada por sua dinamicidade que nos põe, portanto, em contato com um ambiente que se caracteriza pela flexibilidade, não fixidez, mobilidade e plasticidade" (2014, p. 19). Reconhecer que a criação é resultado de um movimento, de algo que é plástico, nos coloca diante de uma suposta dicotomia do campo da educação: a rigidez da educação formal (dos conteúdos escolares, por exemplo) versus a aparente mobilidade dos conhecimentos na educação não formal (as constantes mudanças de exposições e suas temáticas nos museus, por exemplo). Consideramos uma "aparente mobilidade" porque acreditamos que mesmo um ambiente mais livre como o museu pode levar educadores a construir práticas educativas engessadas; e, além disso, criando mais uma ressalva, poderíamos dizer que a falta de mobilidade da educação formal pode ser só aparente também, e que vista de mais perto pode revelar em seus planejamentos movimentos como os dos artistas:

[...] diferentes possibilidades de obra apresentadas nas séries de rascunhos, tratamentos de roteiros, esboços etc.; propostas de obras se modificando ao longo do processo; partes de uma obra reaparecendo em outras do próprio artista; ou ainda fatos lembrados ou livros lidos, sendo levados para obras em construção. (SALLES, 2014, p. 19)

Nos baseamos também em Freire (1978, p. 17) para defender o campo da educação como um espaço de práticas de criação: “o educador deve ser um inventor e um reinventor constante desses meios e desses caminhos com os quais facilite mais e mais a problematização do objeto a ser desvelado e finalmente apreendido pelos educandos". Este educador igualmente demonstrou ao longo de sua vida a preocupação com a guarda dos documentos que registram o percurso do planejamento de projetos na educação. Em seu livro Cartas a Guiné-Bissau (1974), por exemplo, cujo subtítulo era "registros de uma experiência em processo", buscou demonstrar o modo como um projeto de alfabetização foi criado publicando as cartas por meio da qual substancial parte do diálogo com a equipe educativa havia sido estabelecido. Na Introdução, registrou: "Entre publicar um livro, em dois ou três anos mais, uma espécie de relatório final dos trabalhos hoje em curso, e revelar a experiência em pleno andamento, preferi a segunda hipótese.” (FREIRE, 1978, p. 6). 


\section{Contexto de produção do projeto educativo}

De acordo com Salles (2017, p. 123), os sujeitos envolvidos em processos de criação estão sempre "imersos e sobredeterminados por sua cultura", o que significa que todo processo se realiza em um determinado contexto, que envolve questões históricas, políticas, financeiras, entre outras. No caso do Laboratório, suas ações foram desenvolvidas dentro do contexto do Programa Educativo Gente Arteira, que, por sua vez, era gerido por uma empresa terceirizada contratada por tempo determinado por meio de licitação. Tratava-se, portanto, de uma ação financiada por um banco público, a CAIXA Econômica Federal, por meio de sua área voltada à cultura, a CAIXA Cultural. Essa característica do contexto implicava em uma série de obrigações burocráticas de registro, como listas de presença, fotografias e filmagens para a própria CAIXA. De maneira paralela a isso, registros espontâneos eram feitos por cada participante, de acordo com as necessidades que surgiam.

A CAIXA Cultural possui um calendário de exposições temporárias, com duração média de três meses, organizadas por curadores externos, cujos bens culturais são provenientes de coleções particulares, de museus ou, algumas vezes, de seu acervo próprio. A inserção dessas exposições no circuito CAIXA se fazia, até aquela data, por meio de seleção pública, realizada pelo edital do Programa de Ocupação dos Espaços da CAIXA Cultural. De acordo com o objetivo traçado para o Programa Educativo Gente Arteira, ele se propõe a realizar ações educativas que estabeleçam diálogo constante com essas exposições, explorando seu potencial educativo, o que é concretizado por meio de uma agenda permanente de atividades, entre as quais durante 2018 esteve o Laboratório.

Localizar este programa educativo nessa dinâmica de mostras temporárias indica uma de suas principais idiossincrasias, qual seja, a da impossibilidade de se realizar um estudo a longo prazo das coleções expostas, o que impacta nos tipos de ações educativas possíveis de serem desenvolvidas. Ao mesmo tempo, tendo ciência de que a maior porcentagem de público dessas exposições era de turmas de escolares, havia uma preocupação em criar modos de estabelecer vínculos mais profundos com os estudantes. Dentro das pesquisas que se situam na intersecção entre educação em museus e ensino de arte, um dos pontos que se mantém em discussão é a almejada aproximação entre os processos educacionais constituídos dentro das galerias de arte e o ensino de arte nas escolas, tendo em vista que, na maioria das vezes, essa relação se resume a visitas curtas e pontuais de grupos de escolares às exposições, sem a construção de maiores vínculos. É em vista dessa questão e inspirados em uma experiência de 
curadoria colaborativa que havia sido desenvolvida no Museu de Arte Municipal de Curitiba (MuMA) pela pesquisadora Solange Gabre (2016) que tomamos a decisão de desenhar o Laboratório como um projeto com a participação conjunta de estudantes, professores, educadores de museus, famílias e artistas, com uma agenda contínua de encontros. A característica de financiamento público do projeto viabilizava que a participação desses sujeitos fosse gratuita. Para Maria da Gloria Gohn, este é um tipo de encontro necessário, pois

\begin{abstract}
educação não formal parte do suposto de que a educação propriamente dita é um conjunto, uma somatória que inclui a articulação entre educação formal - aquela recebida na escola via matérias e disciplinas, normatizada -, a educação informal que é aquela que os indivíduos assimilam pelo local onde nascem, pela família, religião que professam, por meio do pertencimento, da região, do território e da classe social da família - e a não formal, que tem um campo próprio, embora possa se articular com as duas. (GOHN, 2016, p. 61)
\end{abstract}

Além disso, a autora enfatiza o caráter processual e dialógico desse tipo de educação: “a educação não formal é um processo de aprendizagem, não uma estrutura simbólica edificada e corporificada em um prédio ou em uma instituição; ela ocorre pelo diálogo tematizado" (GOHN, 2016, p. 62). Ainda, afirma que:

\footnotetext{
como há intencionalidades nos processos e espaços da educação não formal, há caminhos, percursos, metas e objetivos estratégicos que podem se alterar constantemente. Há metodologias, em suma, que precisam ser desenvolvidas, codificadas, ainda que com alto grau de provisoriedade, pois o dinamismo, a mudança, o movimento da realidade segundo o desenrolar dos acontecimentos, são as marcas que singularizam a educação não formal. (GOHN, 2016, p. 65)
}

O Laboratório se constituiu como um projeto de educação não formal que visava à formação continuada de educadores de museus e professores e foi realizado em três edições diferentes ao longo do ano de 2018, em parceria com escolas da cidade. Salles (2017, p. 125) afirma que "[a]s redes dos processos ganham mais complexidade quando se pensa em cada um dos membros do grupo imersos e sobredeterminados por sua cultura”. É na relação com os contextos culturais específicos de cada sujeito que "[o]s campos de possibilidade se ampliam e começa a surgir a necessidade de se fazer escolhas, a partir do modo de trabalho e dos critérios da equipe" (SALLES, 2017, p. 125). Assim, começamos a compreender os processos de criação em grupo concretizados no Laboratório ao observar que o projeto se desenvolveu em torno da realização de experiências de colaboração reunindo profissionais da arte e da educação com distintas formações e tempos de profissão, dispostos a debater educação formal e não formal, para planejar juntos experiências educativas em arte nas exposições da galeria 
da CAIXA. Constituíram os grupos, em cada edição, respectivamente: catorze educadores e duas professoras da turma; sete educadores e uma professora da turma; e treze educadores, uma professora da turma e uma pedagoga do centro de educação infantil. A Tabela 1 fornece alguns dados mais específicos sobre o contexto de cada edição do projeto, com a delimitação de uma escola, um público escolar e uma exposição distintos, os quais determinavam o primeiro horizonte de escolhas para os processos de criação em grupo dos planejamentos.

Tabela 1 - Dados do contexto de cada edição do projeto

\begin{tabular}{|c|c|}
\hline \multicolumn{2}{|r|}{$\begin{array}{l}\text { Edição } 1 \\
\text { fevereiro e março de } 2018\end{array}$} \\
\hline Escola & $\begin{array}{l}\text { Colégio Modelo de Curitiba } \\
>\text { Escola particular localizada no bairro Cajuru, Zona Leste da cidade, a } 9,1 \mathrm{~km} \text { da CAIXA } \\
\text { Cultural Curitiba. }\end{array}$ \\
\hline $\begin{array}{l}\text { Público } \\
\text { escolar }\end{array}$ & 21 estudantes do $3 .^{\circ}$ ano do Ensino Médio \\
\hline Exposição & $\begin{array}{l}\text { Portinari: a construção de uma obra } \\
\text { > Mostra de Cândido Portinari em cartaz entre } 17 / 1 \text { e } 22 / 4 / 2018 \text { que reuniu esboços de obras } \\
\text { significativas da trajetória deste artista modernista e esculturas de Sergio Campos, inspiradas } \\
\text { em personagens de quadros de Portinari. }\end{array}$ \\
\hline \multicolumn{2}{|r|}{$\begin{array}{l}\text { Edição } 2 \\
\text { junho de } 2018\end{array}$} \\
\hline Escola & $\begin{array}{l}\text { Escola Municipal CEI Issa Nacli } \\
\text { > Escola pública municipal localizada no bairro Uberaba, Zona Leste da cidade, a 9,5 km da } \\
\text { CAIXA Cultural Curitiba }\end{array}$ \\
\hline $\begin{array}{l}\text { Público } \\
\text { escolar }\end{array}$ & $\begin{array}{l}21 \text { estudantes do } 3 .^{\circ} \text { ano do Ensino Fundamental I, participantes da Oficina de Teatro em } \\
\text { contraturno }\end{array}$ \\
\hline Exposição & $\begin{array}{l}\text { Mundo Giramundo } \\
>\text { Mostra retrospectiva do grupo Giramundo em cartaz entre } 16 / 5 \text { e } 12 / 8 / 2018 \text { que reuniu o } \\
\text { acervo de bonecos de vara, fantoches, marionetes e outros recursos do teatro de animação } \\
\text { criados pelo grupo desde os anos de } 1970 \text {. }\end{array}$ \\
\hline
\end{tabular}

Edição 3

outubro de 2018

\begin{tabular}{cl}
\hline & $\begin{array}{l}\text { Centro Municipal de Educação Infantil Nice Braga } \\
\text { Escola }\end{array}$ \\
& CAIXA Cultural Curitiba. \\
Público & 15 crianças do Pré I (4 e 5 anos) \\
escolar & \\
& $\begin{array}{l}\text { 2. }{ }^{\text {a }} \text { Mostra Bienal CAIXA de Novos Artistas } \\
>\text { Mostra coletiva em cartaz entre 28/8 e 28/10/2018 que reuniu obras de arte contemporânea de } 7 \mathrm{~km} \text { da } \\
\text { trinta artistas brasileiros em início de carreira. }\end{array}$ \\
\hline
\end{tabular}

Fonte: Arquivo dos autores. 
Segundo Salles (2010, p. 70), “a criação realiza-se na tensão entre limite e liberdade. [...] Criar livremente não significa poder fazer qualquer coisa, a qualquer momento, em quaisquer circunstâncias e de qualquer maneira." Localizamos alguns desses limites nos dados da Tabela 1, mas também em um calendário predeterminado a ser cumprido, conforme a Figura 1, que indica os dias específicos para ações na escola e outros na CAIXA e momentos para se estar somente entre educadores, planejando, e outros para se estar com os estudantes, aplicando o que foi planejado, conforme aponta a legenda do calendário. A partir dessa dinâmica, os envolvidos tinham oportunidade de sair de seus lugares habituais de exercício profissional (os educadores de museus podiam circular pela escola e os professores pelo museu); uma turma inteira de escola era beneficiada pelas ações planejadas; e a capacidade de todos em estar com os outros e de escutá-los era praticada. Com isso, eram exercitadas outras formas de ocupar uma galeria de arte e de transpor didaticamente os conhecimentos que as exposições ofereciam. 
Figura 1 - Calendário de encontros nas três edições

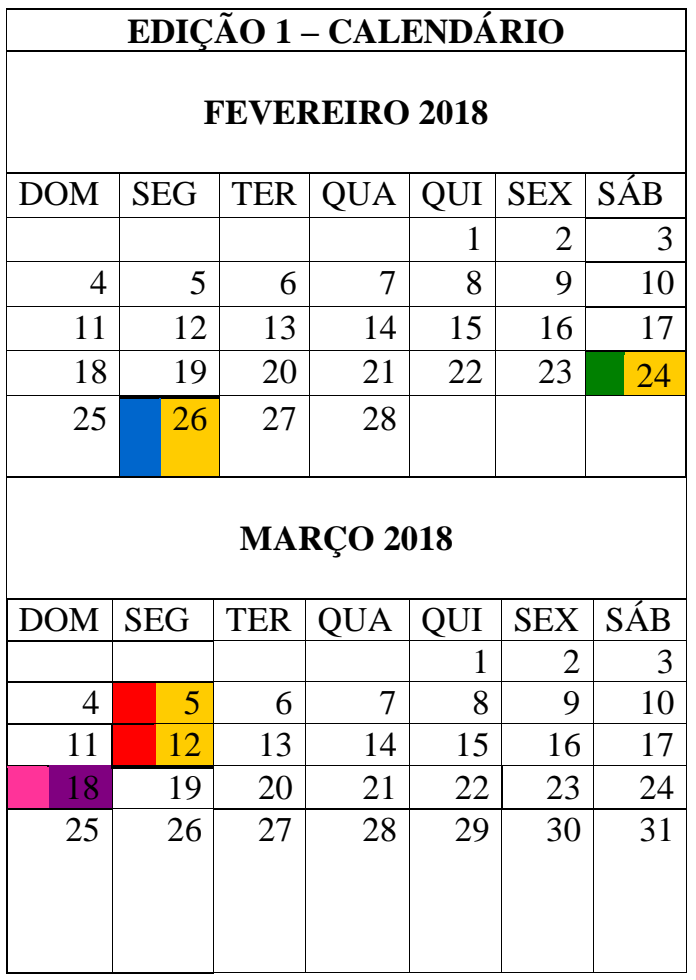

\begin{tabular}{|c|c|c|c|c|c|c|}
\hline \multicolumn{7}{|c|}{ EDIÇÃO 2 - CALENDÁRIO } \\
\hline \multicolumn{7}{|c|}{ JUNHO 2018} \\
\hline DOM & SEG & TER & QUA & QUI & SEX & SAB \\
\hline & & & & & 1 & 2 \\
\hline 3 & 4 & 5 & 6 & 7 & 8 & 9 \\
\hline 10 & 11 & 12 & 13 & 14 & 15 & 16 \\
\hline 17 & 18 & 19 & 20 & 21 & 22 & 23 \\
\hline 24 & 25 & 26 & 27 & 28 & 29 & 30 \\
\hline \multicolumn{7}{|c|}{ JULHO 2018} \\
\hline DOM & SEG & TER & QUA & QUI & SEX & SAB \\
\hline & 2 & 3 & 4 & 5 & 6 & 7 \\
\hline 8 & 9 & 10 & 11 & 12 & 13 & 14 \\
\hline 15 & 16 & 17 & 18 & 19 & 20 & 21 \\
\hline 22 & 23 & 24 & 25 & 26 & 27 & 28 \\
\hline 29 & 30 & 31 & & & & \\
\hline
\end{tabular}

\begin{tabular}{|r|r|r|r|r|r|r|}
\hline \multicolumn{7}{|c|}{ EDIÇÃO 3 - CALENDÁRIO } \\
\hline \multicolumn{7}{|c|}{ OUTUBRO 2018 } \\
\hline DOM & SEG & TER & QUA & QUI & SEX & $\begin{array}{l}\text { SÁ } \\
\text { B }\end{array}$ \\
\hline & 1 & 2 & 3 & 4 & 5 & 6 \\
\hline 7 & 8 & 9 & 10 & 11 & 12 & 13 \\
\hline 14 & 15 & 16 & 17 & 18 & 19 & 20 \\
\hline 21 & 22 & 23 & 24 & 25 & 26 & 27 \\
\hline 28 & 29 & 30 & 31 & & & \\
\hline
\end{tabular}

\begin{tabular}{|l|l|}
\hline \multicolumn{1}{|c|}{ LEGENDA } \\
\hline & $\begin{array}{l}\text { Apresentação | Visita na } \\
\text { exposição com os educadores }\end{array}$ \\
\hline & Planejamento do encontro seguinte \\
\hline & Visita na Escola \\
\hline & Visita na CAIXA Cultural \\
\hline & Visita das famílias e amigos \\
\hline & Encerramento $\mid$ Avaliação \\
\hline
\end{tabular}

Fonte: Arquivo dos autores.

\section{Construir um projeto colaborativo a partir do diálogo}

[...] se soubéssemos o que as outras pessoas fabricam com aquilo que lhes damos [através das palavras], ficaríamos muito espantados. A linguagem é feita assim, de desvios, apropriações, alterações. Não tenho certeza de que ela sirva para "comunicar", mas sim para criar mal-entendidos incessantemente renovados, alguns deles divertidos como uma peça de Feydeau, outros lamentáveis. Mas com esses deslizes, essas aproximações, esses deslocamentos de sentido, esses lapsos, essas descobertas, nós chegamos a sonhar, a pensar. Nós procuramos uns aos outros tateando, nos esbarramos. E de tempos em tempos, nos encontramos. 
Ao pensar sobre o diálogo, em um primeiro momento, podemos situá-lo somente no campo da vida prática. Contudo, tal noção pode alcançar dimensões psicanalíticas e filosóficas se refletirmos a partir de autores como Michèle Petit e Paulo Freire. Para a autora, é pelos desentendimentos nascidos das palavras que conhecemos uns aos outros e é pelas falhas inerentes à linguagem que nos comunicamos. Para o autor, por sua vez, o diálogo "faz parte da própria natureza histórica dos seres humanos", pois "[é] parte de nosso progresso histórico do caminho para nos tornarmos seres humanos" (FREIRE, 1986, p. 64). Dialogar, em ambos os casos, é uma ação que nos transforma e é base fundante do aprendizado e do crescimento individual e social. Salles $(2017$, p. 137) menciona que é por meio de práticas comunicativas que um projeto comum a um grupo se constitui. É nesse sentido que o diálogo entre os sujeitos envolvidos no Laboratório era fundamental para o desenvolvimento do projeto, pois era das trocas de palavras e dos silêncios entre as pessoas que surgiam os planejamentos e as situações de aprendizado ou, em termos de processo de criação em grupo, que os "objetivos de um projeto comum" se tornavam explícitos (SALLES, 2017, p. 144). Compartilhando do ponto de vista de Freire, podemos entender que era por meio dessa dimensão social da comunicação que conseguíamos intervir na realidade:

\begin{abstract}
Ao nos comunicarmos, no processo de conhecimento da realidade que transformamos, comunicamos e sabemos socialmente, apesar de o processo de comunicação, de conhecimento, de mudança, ter uma dimensão individual. Mas o aspecto individual não é suficiente para explicar o processo. Conhecer é um evento social, ainda que com dimensões individuais. O que é o diálogo, neste momento de comunicação, de conhecimento e de transformação social? O diálogo sela o relacionamento entre os sujeitos cognitivos, podemos, a seguir, atuar criticamente para transformar a realidade. (FREIRE, 1986, p. 65)
\end{abstract}

A Tabela 2, abaixo, lista as categorias das pessoas envolvidas no projeto. No âmbito do planejamento do projeto, o primeiro passo consistia em aprová-lo junto à gestão da instituição cultural financiadora e para isso ele foi sistematizado por escrito. No documento correspondente, chamado Relatório de Controle Oficinas - CAIXA Cultural, foi inserida em meio ao texto uma tabela intitulada Design de Participação (Tabela 2), que continha as colunas Sujeitos Envolvidos e Atribuições. A apresentação da tabela visava contornar "a dificuldade de se conviver com a incerteza na coletividade" (SALLES, 2017, p. 138), pois definia as atribuições básicas de cada pessoa. No primeiro encontro em grupo, o conteúdo era lido e debatido, para esclarecer a todos seus papéis e conseguir delimitar um modo de trabalho, "maneiras [de] como se dá a interação entre os sujeitos" (SALLES, 2017, p. 165). Esse modo de trabalho acordado concretizava o que, no contexto desse projeto, chamávamos 
de "colaborativo". A tabela foi alterada nas três edições do projeto, o que revelam as versões de documentos de Word datados de 3 de abril, 10 de julho e 7 de novembro de 2018. As alterações foram resultado de tomadas de consciência sobre a participação de novos sujeitos que se tornaram importantes no decorrer das edições.

Tabela 2 - Categorias das pessoas envolvidas no projeto e suas atribuições

\section{Design de Participação}

\section{Sujeitos envolvidos \\ 1. Oficineiros (mediadores culturais da CAIXA Cultural Curitiba) \\ 2. Educadores externos (inscritos na oficina)}

3. Professoras da turma de estudantes

4. Estudantes

5. Famílias

6. Artistas

\section{Atribuições}

Articulação entre todos os sujeitos envolvidos na formação. Planejamento e execução de atividades de mediação cultural com estudantes na galeria. Avaliação das atividades.

Planejamento e execução de atividades de mediação cultural com estudantes na galeria. Avaliação das atividades.

Articulação na escola para participação dos estudantes. Seleção dos conteúdos presentes no seu planejamento.

Participação nas atividades propostas na galeria. Mediação do público na galeria no último encontro. Engajamento das famílias para visita à galeria.

Participação nas atividades propostas na galeria no dia do encerramento.

Diálogo com os participantes, por meio de qualquer mídia.

Fonte: Arquivo dos autores.

Desde a primeira edição, foi planejado, mas não sistematizado, que seria feito um convite para que familiares estivessem presentes no último encontro (sempre um domingo) participando de uma visita mediada pelos estudantes. A diferença entre planejamento e sistematização aqui significa que tínhamos uma intenção, mas não havíamos realizado a ação prática de escrevê-la, ou seja, de sistematizá-la. Ao final da Edição 1, percebemos que não ter escrito tornou essa intenção vaga e imprecisa, já que tivemos poucos familiares visitando a galeria. O cotejamento das versões das tabelas nos planejamentos das edições 1 e 2 mostra que apenas na tabela da edição 2 se inseriu a linha "5. Famílias". Isso significa que havíamos percebido que a escrita torna as ideias mais tangíveis e com mais possibilidade de realização prática. Com essa mudança o projeto ganhou uma nova camada de complexidade, porque se 
admitiu de maneira mais explícita o desejo de relacionar os espaços museu, escola e casa, por meio de uma articulação mais efetiva entre os sujeitos envolvidos.

Na tabela da Edição 3, houve quase nenhuma alteração em relação à Edição 2, exceto pela seguinte nova atribuição aos estudantes: "Engajamento das famílias para visita à galeria [...]”. A busca por envolver pais, irmãos e outros familiares em uma visita à mostra, como se vê, foi crescente e intermitente ao longo das edições. Esse incentivo era proveniente de nossa concepção de arte como mediadora das relações entre as pessoas, tal como defende Petit (2019, p. 109): “A literatura, oral ou escrita, a arte sob múltiplas formas (inclusive o artesanato ou a arte de conceber um jardim), por vezes a ciência, são maravilhosos intercessores entre o mundo e nós, entre paisagens exteriores e interiores, mas também entre pais e filhos [...].” Ainda, por estarmos de acordo com Petit quando esta sustenta que o papel da família nos processos de mediação cultural está ligado à criação de um "um vínculo, uma atitude". Para ela, "[o]s frequentadores habituais de museus, concertos, espetáculos de arte dramática ou livrarias são, em grande medida, pessoas que cresceram em ambientes nos quais lhes foi contado e demonstrado, dia após dia, que esses espaços culturais eram "necessários"” (2019, p. 151).

Explicitar a participação das famílias na tabela foi acompanhada de uma transformação nos modos de comunicar a elas o convite para que fizessem parte do projeto: as mudanças se deram em vista de contextualizar melhor a ação que estava sendo desenvolvida na CAIXA Cultural. Estava em jogo, nesses momentos, uma tomada de decisão sobre o modo de comunicar um projeto comum a sujeitos que não conviviam nos mesmos espaços que os demais integrantes do grupo: as famílias não frequentavam a galeria e estavam sempre somente de passagem pela escola. Como fazer chegar a elas o desejo de que visitassem a exposição? Na Edição 1, o convite foi feito enviando um template digital pelo aplicativo da escola aos pais. Na Edição 2, os educadores optaram por criar um quebra-cabeça para presentear as crianças: na frente, havia uma imagem de um boneco da exposição Mundo Giramundo; no verso, uma carta-convite assinada por um fantoche que acompanhou todos os encontros, o Chico da Paraíba. Na Edição 3, foi desenvolvido um vídeo de 3min26s para circular pelo WhatsApp chamado A turma esconde-esconde em: A Careca da Natasha, buscando aproveitar o envolvimento da turma com a obra da artista Natasha Ulbrich. Nele havia uma pequena história utilizando fotos e desenhos produzidos pelas crianças. Em nenhuma das edições tivemos participação massiva das famílias; entretanto, as pessoas que 
estiveram presentes em geral se envolveram bastante nas práticas de criação plástica propostas, como se observa, por exemplo, na Figura 2:

Figura 2 - Participação das famílias na Edição 3

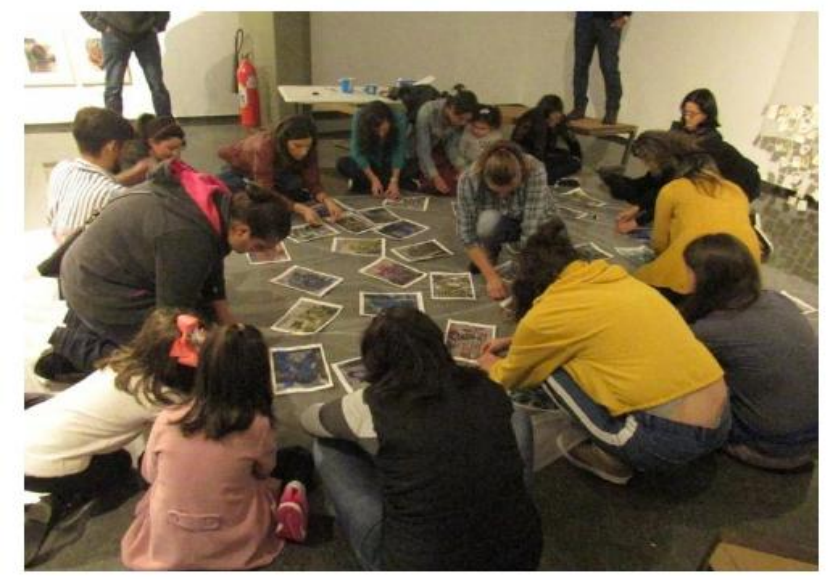

Fonte: Arquivo dos autores. Fotografia de Ariane Salgado

A educadora Alessandra Ferreira construiu uma análise sobre o que, para ela, gerou o forte envolvimento das famílias na prática desenvolvida na Edição 3 (Figura 2):

\begin{abstract}
Os pais na verdade não têm muito repertório sobre como é que eu me comporto nesse momento com as crianças. Então realmente é muito difícil que eles cheguem e já fiquem disponíveis para participar. E isso foi acontecendo aos poucos e eu achei interessante que essa última atividade, que é a costura, ela essencialmente cobrava que o adulto estivesse junto. As crianças não têm autonomia de fazerem sozinhas. Então se criou um contexto em que os pais tiveram que participar. Então eu vi ali que os poucos que ainda estavam distantes, nesse momento acabaram se envolvendo, porque ali a ação deles se tornou indispensável. [...] Se fosse talvez no começo, talvez fosse mais difícil, porque é algo que durante o percurso foi sendo construído para esse adulto entrar mais forte na ação também. (FERREIRA, 2018, $1 \min 13 \mathrm{~s})$
\end{abstract}

Em relação ao processo de tomada de consciência sobre as funções de novos sujeitos, materializado na tabela, após a finalização da Edição 3 surgiu uma nova alteração: incluiu-se a linha "6. Artistas: Diálogo com os participantes, por meio de qualquer mídia". A alteração foi feita para a apresentação de um relato de experiência no evento Novos Olhares (no MISSP, em 10 dez. 2018) e tratava-se da sistematização de algo que já havia acontecido: a obra da artista Natasha Ulbrich ganhou especial destaque na relação das crianças com a exposição Bienal CAIXA de Novos Artistas e por isso o grupo de educadores decidiu contatar Ulbrich, pedindo algum tipo de mensagem para as crianças. A artista enviou um vídeo de $2 \mathrm{~min} 2 \mathrm{~s}$, contando o processo de criação da obra. O diálogo por WhatsApp com ela (que vive em Porto Alegre-RS) apontou o valor da ampliação dessa rede de envolvimento também para a própria artista, conforme seu depoimento: 
Eu estava bem nervosa, é a primeira vez que participo de um evento com educativo, estou muito feliz mesmo que as crianças tenham gostado do trabalho, pois eu me lembro que foi desde pequena que comecei a me interessar pela arte por causa das visitas a museus e exposições. É muito legal também ter que pensar o trabalho e como explicar ele através do olhar da criança, um belo exercício para pensar a essência do trabalho. Agradeço muito o pedido e as fotos, adorei participar do projeto. (19/10/2018, 16h09min)

Ao longo do projeto, foram criados questionários com a intenção de recolher por escrito impressões e reflexões dos participantes. Desde o princípio, acreditávamos que por meio dessas escritas teríamos possibilidade de avaliar as ações desenvolvidas, mas não tínhamos um pensamento elaborado sobre como realizar isso. Foi somente após um distanciamento ao conjunto das três edições que compreendemos que a coleta desse material escrito havia sido importante porque poderia ser colocado em diálogo com outros documentos que não haviam sido intencionalmente produzidos. São essas relações que viabilizam o estudo dessa experiência educativa sob um ponto de vista de processo, a partir da crítica de processos criativos (SALLES, 2014).

Nesses documentos, encontramos registros diversos que apontam como se deu a primeira aproximação entre educadores e estudantes em cada edição. Um processo de criação se dá dentro de um "espaço geográfico e social, com restrições e possibilidades de deslocamentos" (SALLES, 2010, p. 125) e, neste ponto, identificamos uma particularidade do espaço de criação desse projeto educativo: havia uma preocupação em relação à circulação entre a escola e a CAIXA, a fim de garantir uma aproximação às referências culturais e sociais dos estudantes e dos professores, para criar uma experiência com as exposições que viesse a dialogar melhor com aquela realidade escolar. Essa prática tirava a galeria do centro do projeto, equilibrava sua importância em relação ao espaço escolar, gerava maior empatia entre os envolvidos e viabilizava mais dados para se construir os planejamentos dos encontros subsequentes. A escrita de algumas educadoras aponta suas percepções sobre esse dia: Ana Claudia de Araujo escreveu sobre o valor, para sua vida profissional, de conhecer mais de perto uma escola municipal de Curitiba: "Eu pude ampliar meus conhecimentos sobre a Rede Municipal de Ensino de Curitiba, descobrir possibilidades de atuação e criar vínculos com colegas que, de outra maneira, não conseguiria. Gostaria de receber atividades como essa frequentemente." (Folha de avaliação, 18/6/2018). Elena Aparecida Pereira redigiu uma reflexão sobre como a ida à escola era esclarecedora para quem recebia e para quem era recebido: 
[...] são inúmeras as oportunidades de trabalhar em parceria e é necessário trabalhar junto com professores e a pedagoga para eles verem como o projeto funciona, pois muitas escolas nem se interessam em saber o conteúdo da exposição previamente para conversar com os alunos [...] Como foi importante ir na escola, conhecer o habitat, o lugar onde eles passam a maior parte do seu tempo. Achei muito rica a experiência, cada criança tem suas particularidades [...]. (Folha de avaliação, $18 / 6 / 2018)$

A experiência deste primeiro encontro na escola durante a Edição 1 viabilizou um interessante debate a respeito do conceito de diálogo. A dinâmica planejada para o dia foi a produção de retratos em duplas, utilizando materiais como carvão, lápis sépia e sanguínea, tais como os utilizados por Cândido Portinari em seus esboços de retratos. Foi acordado que o fundo de cada retrato deveria ser preenchido com elementos que mostrassem aquilo que se descobriu durante a conversa com a dupla, como seus gostos, profissão, sonhos etc. Em princípio, havia um clima de expectativa e de dúvidas sobre como se aproximar do grupo de adolescentes. O educador Cadu Cinelli registrou:

Precisei lidar com os meus preconceitos com o espaço educacional e a forma infatilizadora de como se trata o adolescente (como aquele que é bobo ou imaturo, aquele que se dispersa e necessita ser agradado). Precisei me relembrar de descontextualizar os estereótipos do adolescente para pensar na proposta para uma "pessoa viver uma experiência artística, portanto criativa". (Diagnóstico Semanal, 26/2/2018)

Em dezenove dos vinte e três questionários respondidos nesse dia pelos estudantes havia menções à interação com os educadores como algo positivo. A estudante Maria Eduarda Camers, por exemplo, destacou: “[...] foi algo muito produtivo, divertido, [...] tive oportunidade de conhecer pessoas incríveis" (Folha de Feedback, 27/2/2018). A Figuras 3 e 4 mostram a interação entre duas duplas e um dos retratos produzidos:

Figuras 3 e 4 - Prática de desenho de retratos no primeiro encontro entre educadores e estudantes na Edição 1

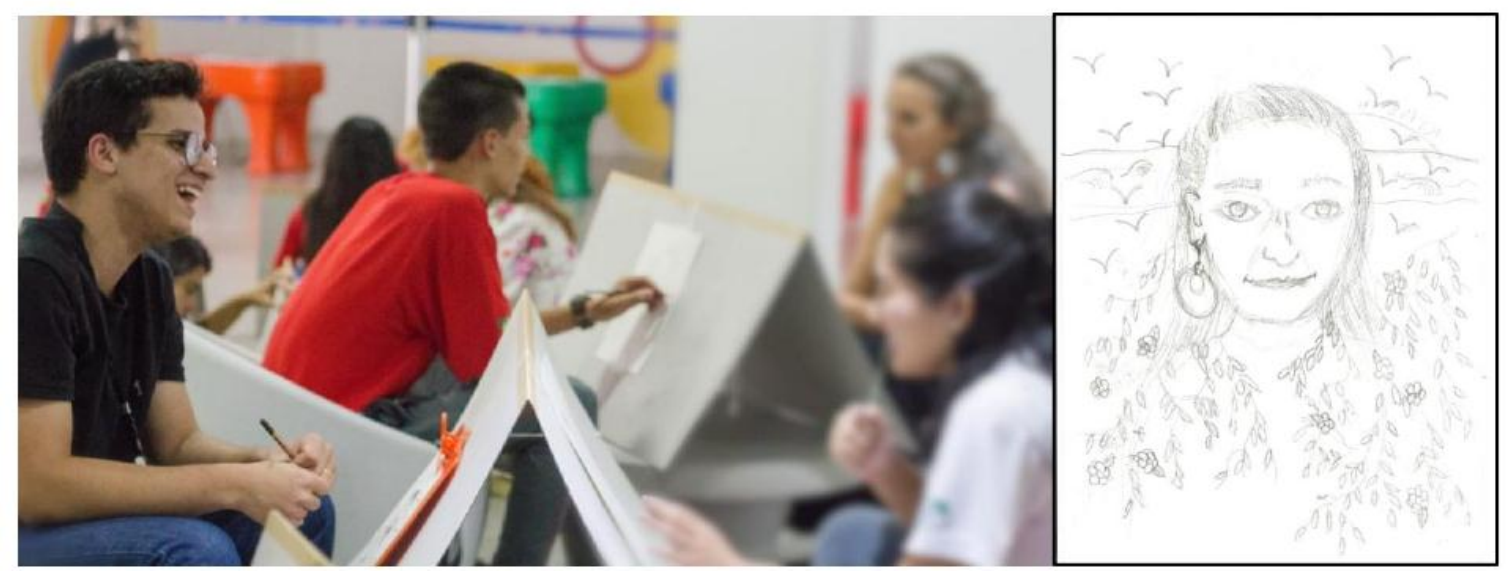

Fonte: Arquivo dos autores. Fotografia de Lia Bianchini. 
Esse resultado positivo na interação entre educadores e estudantes fez com que nos planejamentos dos novos encontros buscássemos estimular ainda mais as conversas em pequenos grupos. Vimos nesse momento acontecer uma tomada de decisão em grupo que propiciou "a formação de linhas de força" (SALLES, 2017, p. 128), ou seja, o surgimento de fios condutores que passaram a direcionar a criação dos planejamentos. Porém, após o terceiro encontro com a turma, em que, divididos em pequenos grupos de alunos e educadores, foi realizada uma atividade de esquetes teatrais com registro fotográfico baseadas nos nichos temáticos da exposição, houve a demanda de repensar o espaço do diálogo estabelecido entre alunos, professoras e educadores. Uma educadora e as professoras da turma pontuaram esse dado em suas avaliações: "Como já dissemos no coletivo, os educadores precisam falar menos e abrir espaço para os estudantes se posicionarem.” (Solange Gabre, Diagnóstico Semanal, 12/3/2018). "Entrosamento muito bom, mas os alunos sentiram-se 'acuados' e quase não falaram.” (Lucilene Cardoso, Diagnóstico Semanal, 12/3/2018). “Os alunos gostaram muito da proposta. Porém, relataram que vários 'instrutores' falaram demais." (Geny Santos Nowisck, Diagnóstico Semanal, 12/3/2018). Notamos nesse momento que nem todos os educadores tinham o mesmo entendimento sobre o que significava criar espaços de diálogo com os estudantes e que isso colocou em xeque um princípio direcionador das ações do grupo.

A situação problemática a respeito do diálogo nos estimulou, enquanto articuladores do projeto, a buscar algum dispositivo para que o problema diagnosticado fosse abordado de maneira integrada, dialógica, sem que os educadores se sentissem acusados pela situação. $\mathrm{O}$ dispositivo encontrado foi uma ficha de papel quadrada, de fundo preto e com a frase escrita em branco: "por que calar?". Ela foi usada durante o último encontro com os educadores (Figura 5), momento em que o grupo pôde dar seu retorno quanto à participação no projeto e avaliar o Laboratório como um todo. 
Figura 5 - Roda de conversa com a ficha "por que calar?"

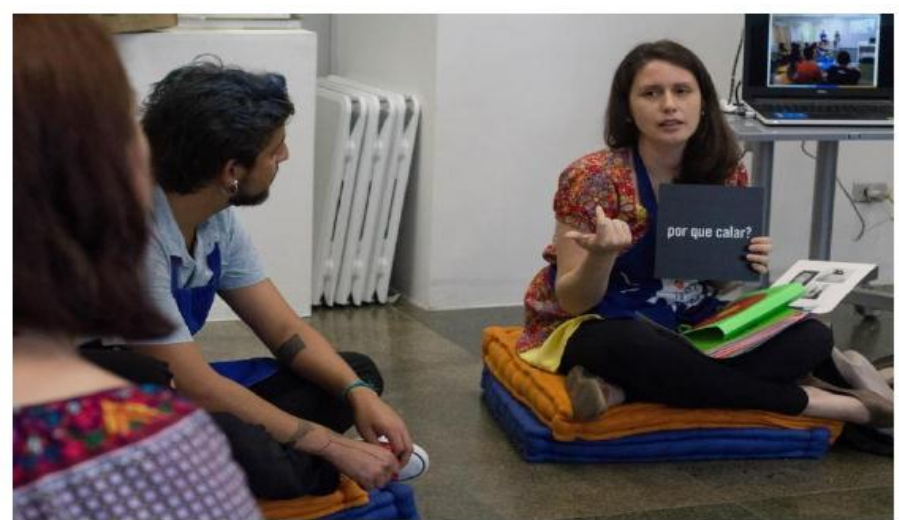

Fonte: Arquivo dos autores. Fotografia de Lia Bianchini.

A ficha, que faz parte do Material Educativo da 29. ${ }^{a}$ Bienal de São Paulo (2010), foi apresentada a fim de abrir uma conversa franca sobre os espaços de diálogo estabelecidos com o grupo de estudantes. A citada edição da Bienal de São Paulo incorporou o conceito de Terreiro como subdivisões temáticas, curatoriais e de espaço. A ficha em questão, "por que calar?", aborda as ideias do terreiro nomeado "Dito, não dito, interdito". Em seu verso, há um recorte de artistas presentes na exposição que se inserem nesse nicho/terreiro e alguns questionamentos a respeito da fala, da entonação e do diálogo, como quando instiga que "ao pensar nas palavras que usamos e nas diferentes maneiras de falar a mesma frase, podemos começar a entender porque existem tantas falhas de comunicação. [...] Desafios de entendimento fazem parte do convívio entre as pessoas". Da mesma forma, Paulo Freire (1996) aborda em Pedagogia da Autonomia:

\begin{abstract}
Somente quem escuta paciente e criticamente o outro, fala com ele, mesmo que, em certas condições, precise de falar a ele. O que jamais faz quem aprende a escutar para poder falar é falar impositivamente. Até quando, necessariamente, fala contra posições ou concepções do outro, fala com ele como sujeito da escuta de sua fala crítica e não como objeto de seu discurso. O educador que escuta aprende a difícil lição de transformar o seu discurso, às vezes necessário, ao aluno, em uma fala com ele. (FREIRE, 1996, p. 113, grifos no original)
\end{abstract}

A inserção da ficha nesse dia de fechamento foi essencial para abordar a situação de diálogo falho que foi levantada por alguns educadores e estudantes, dando espaço para que todos os educadores pudessem expor suas percepções sobre as dinâmicas com os alunos, assim como repensar suas próprias abordagens em outros espaços educativos. Puderam-se notar diferentes respostas para a pergunta da ficha, salientando que calar, às vezes, é dar espaço à percepção do outro e para si próprio, transformando a experiência individual de maneira coletiva. 
Os professores das turmas eram estimulados a trazer feedbacks ao grupo de educadores sobre questões diversas que surgissem na escola. No encontro de fechamento da Edição 3, a professora Ester das Neves Silva, pedagoga de formação, narrou uma tensão vivida na escola, antes do início do projeto, que envolve questões de ordem política do contexto de produção deste projeto educativo. As situações polêmicas ocorridas nas exposições Queermuseu (Santander Cultural, Porto Alegre-RS) e na performance de Wagner Schwartz no 35. ${ }^{\circ}$ Panorama da Arte Brasileira (MAM, São Paulo-SP) no ano de 2017 haviam deixado escolas, famílias e instituições culturais do Brasil em alerta em relação às temáticas de exposições de arte e esse medo passou a ser um pano de fundo de qualquer visita a mostras de arte desde então. Nesse contexto, uma professora que não estava envolvida no Laboratório questionou a participação das crianças, pois, para ela, a exposição possuía obras chocantes para a faixa etária da educação infantil. Na Bienal CAIXA de Novos Artistas, as obras "Presente" (2015) e "O Corte - uma intervenção no corpo" (2016), de Joana Bueno, com imagens dos seios e a retirada da prótese de silicone da própria artista, e "Fragmentos de um corpo" (2016), de Natalie Mirêdia, também com imagens de seios da artista, constituíram o núcleo do medo vivido pela docente. Ester das Neves Silva, apesar da oposição da colega, optou por manter a turma no projeto e, ao término da vivência, expôs uma reflexão ao grupo:

Eu queria entender o lado que vocês olham. E como não é a minha área, eu vou olhar... Eu fiquei um tempão lá em cima, naquele lugar, tentando entender o que uma artista olhou e tentou produzir com aquilo lá. O que ela pensou, o que ela estava pensando... Porque cada vez que eu ía no museu e olhava no geral achava o "oh" aquelas tintas jogadas lá [...] e eu falava "o que eles pensam?". Mas a gente vai lendo, a gente vai tendo aula, as pessoas vão falando, [...] então eu tentava olhar com olhar de artista, não é? Então naquela, quando eu cheguei aqui, eu fiquei olhando... $\mathrm{O}$ que ela pensou? O que ela estava passando no momento? O que ela está querendo dizer para a gente? Como mulher, como pessoa, como artista... E daí eu saí daqui confusa, [e pensei] vamos ver o que eles vão dizer, né? Eu estava muito mais curiosa para ver o resultado de vocês, que são da área, porque podem explicar mais ou menos a intenção do artista. Porque eles [os artistas] não estão aqui para explicar: "Ah, eu pensei isso, estive num lugar, fui numa exposição, eu achei legal esse material e tentei usar no meu trabalho". Eles não estão aqui para explicar, mas alguma coisa eles estão trazendo para você. (SILVA, 2018, 21min45s)

Apesar da discussão provocada, as citadas obras não foram exploradas com as crianças, pois eram apenas três das trinta e sete presentes na exposição. A educadora Alessandra Ferreira observou: "Não tivemos que ir [nas obras polêmicas], mas ao mesmo tempo também não era algo velado. [...] Era algo que estava aberto ali, mas na verdade elas [as crianças] estavam dentro de um contexto de um percurso em que aquele repertório oferecido já era suficiente." (FERREIRA, 2018, 25min). Quando somos capazes de analisar 
uma exposição como um objeto cultural composto por diversas camadas, identificamos que há muitos discursos/trajetos disponíveis e que podemos escolher por quais queremos caminhar. Assim, mesmo uma exposição de arte contemporânea que em um olhar rápido não teria nada para oferecer às crianças pequenas, viabilizou uma grande quantidade de experiências. Para o grupo de educadores desta edição, isso se apresentou na forma de experiência, porque não lhes foi dito que isso poderia ser feito: todos viveram a criação em conjunto dos planejamentos para as visitas das crianças e puderam observar suas reações.

\section{Considerações finais}

Acreditamos que uma das principais reflexões viabilizadas por este estudo é a de que diálogo entre museu e escola não é algo abstrato, que ocorre entre instituições: diálogo se constrói por meio da interação entre pessoas, pois os documentos de processo estudados aqui possuem autoria, foram feitos por sujeitos. Nesse sentido, para que projetos entre instituições se tornem mais densos e fecundos, é necessário que as pessoas que os fazem estejam dispostas a falar e a escutar, a fim de selar "o relacionamento entre os sujeitos cognitivos" e transformar a realidade (FREIRE, 1986, p. 65). Ao final, foi possível notar uma diferença positiva sensível de interação dialógica entre as escolas envolvidas no Laboratório e a CAIXA Cultural Curitiba, em comparação com as visitas escolares normais que ocorrem na instituição. De modo geral, ainda, em todas as edições, foi possível observar como as propostas de prática de criação plástica coletivas eram momentos de intensificação de diálogo nos grupos.

A reflexão sobre como avaliar uma prática educativa complexa como o Laboratório se transformou ao longo das experiências. Na Edição 1, criamos questionários para serem respondidos, que também se alteraram com o tempo. Conseguimos registros interessantes neles, mas o ciclo das três edições mostrou que a totalidade de registros feitos e não somente os questionários respondidos eram materiais para avaliação. Para desenvolver este estudo, utilizamos documentos físicos e digitais, em texto, som e imagem (fixas e em movimento). Com isso, buscamos demonstrar a importância do arquivamento dos mais diversos registros das ações educativas, pois a possibilidade de avaliar o que ocorreu será tanto mais rica quanto mais documentos existirem para serem relacionados entre si. Os documentos de processo revelam os movimentos que realizamos e as intenções por trás de cada mudança, por isso estudar processo é esmiuçar o como fazer. 
Ao longo do projeto recebemos muitos feedbacks positivos dos participantes, mas também diversos pedidos da instituição promotora para rever a justificativa de sua realização, em vista do seu tempo de duração versus a quantidade de pessoas beneficiadas. De um ponto de vista quantitativo, era difícil justificar, porque dedicávamos seis encontros ao longo de um mês a um grupo de cerca de cinquenta pessoas - um número interpretado como pequeno naquele contexto, cujas especificidades não conseguiremos debater aqui. Por isso, este artigo reúne de alguma forma uma resposta qualitativa a esses questionamentos institucionais, que colocavam em xeque o desenvolvimento da proposta. Sabemos que esse tipo de embate é corriqueiro em muitos espaços de educação e por isso o que propomos aqui é também uma forma de compartilhar com outros educadores estratégias para sistematizar resultados de forma a embasar uma argumentação em prol da qualidade em detrimento da quantidade. Assim, acreditamos contribuir para um entendimento sobre a profundidade que o trabalho educativo pode alcançar quando encaminhado sob uma perspectiva qualitativa e não somente quantitativa.

Percebemos uma tendência recente em diferentes museus por construir processos educativos com base na colaboração. Tal como Salles (2017) identifica em áreas como o teatro e o cinema, percebemos que nos museus também não há uma generalização que defina o sentido da palavra colaboração, pois cada projeto possui suas especificidades. No caso do Laboratório, acreditamos que as ações de colaboração revelaram modos de atuar dentro das instituições de forma transversal, a fim de usufruir de infraestruturas viáveis e, ao mesmo tempo, contribuir criativamente para as mudanças necessárias nelas. A colaboração como premissa de relação entre os participantes nos grupos fortaleceu o desenvolvimento do projeto, pois cada sujeito, mesmo que em diferentes medidas, pôde contribuir a partir de suas próprias trajetórias acadêmica, profissional e poética. De acordo com Salles (2017), as pesquisas na área de processos criativos em grupo ainda são escassas, e, a partir desse dado, vemos a aplicação da crítica de processos criativos à análise dos processos em grupo nos museus como uma possibilidade de expansão tanto dos estudos de crítica quanto das práticas colaborativas nos museus. 


\section{Referências}

FERREIRA, Alessandra. Encerramento/Avaliação Edição 3. [21 out. 2018]. Pesquisadores: Ariane Alfonso Azambuja de Oliveira Salgado e Bruno Ferreira de Souza. Curitiba, 2018. 1 arquivo de audiovisual (gravação em vídeo: VID_20181021_125245544, 28min14s).

FREIRE, Paulo. Cartas à Guiné-Bissau: registros de uma experiência em processo. 4. ${ }^{\mathrm{a}}$ ed. Rio de Janeiro: Paz e Terra, 1978.

FREIRE, Paulo; SHOR, Ira. Medo e Ousadia: o cotidiano do professor. Tradução de Adriana Lopez. Rio de Janeiro: Paz e Terra, 1986.

FREIRE, Paulo. Pedagogia da Autonomia: saberes necessários à prática educativa. São Paulo: Paz e Terra, 1996. Coleção Leitura.

FREIRE, Paulo. Professora Sim, Tia Não: cartas a quem ousa ensinar. 12. a ed. São Paulo: Olho D’Água, 2002.

GABRE, Solange de Fátima. Para Habitar o Museu com o Público Infantil: uma proposta de formação colaborativa entre professoras da infância e profissionais do Museu Municipal de Arte de Curitiba. 2016. Tese. Faculdade de Educação. Programa de Pós-Graduação em Educação. UFRGS, Porto Alegre-RS.

GOHN, Maria da Glória. Educação não formal nas instituições sociais. Revista Pedagógica, Chapecó, v. 18, n. 39, p. 59-75, set./dez. 2016.

MOSTRA Bienal CAIXA de Novos Artistas, 2017/2018 (2.a). Catálogo. [s.l.]: CAIXA Cultural, 2018. il. Color.

MOSTRA Mundo Giramundo. Catálogo. Concepção de projeto: Marcos Malafaia. Curadoria: Beatriz Apocalypse, Ulisses Tavares, Marcos Malafaia. [s.l.]: CAIXA Cultural, 2018. il. Color.

PETIT, Michèle. Ler o Mundo: experiências de transmissão cultural nos dias de hoje. Tradução de Julia Vidile. São Paulo: Editora 34, 2019.

PORTINARI: a construção de uma obra. Catálogo. Idealização e curadoria: Luiz Fernando Dannemann. Realização: Dannemann Entretenimento. [s.l.]: CAIXA Cultural, 2018. il. Color.

SALLES, Cecília Almeida. Arquivos de Criação: arte e curadoria. Vinhedo: Editora Horizonte, 2010.

SALLES, Cecília Almeida. Processos de Criação em Grupo: diálogos. São Paulo: Estação das Letras e Cores, 2017.

SALLES, Cecília Almeida. Redes da Criação: construção da obra de arte. 2a ed. Vinhedo: Editora Horizonte, 2014. 
SILVA, Ester das Neves. Encerramento/Avaliação Edição 3. [21 out. 2018]. Pesquisadores: Ariane Azambuja Salgado e Bruno Ferreira. Curitiba, 2018. 1 arquivo de audiovisual (gravação em vídeo: VID_20181021_125245544,28min14s). 